\title{
Outdoor-Based Education Camp: An Essential Tool to Promote Leadership Skills
}

\author{
Evelyn Ewe Lin Yeap, Rosmiza Mokhtar, Mohd Anwar Muslimen, Farhaniza Ghazali, and Mohd Ariff \\ Ahmad Tarmizi
}

\begin{abstract}
This study seeks to examine if a three days two nights Outdoor-based Education Camp (OBEC)module designed with 8 leadership-basedactivities helps in developing undergraduates' leadership skill through their self-assessments. This study employs a set of questionnaire to examine students' leadership skills after going through the campin an outdoor-based environment. A total of 43 students from Universiti Tenaga Nasional (UNITEN) were involved in this study. Interviews were also conducted to gauge students' feedbacks how they think the activities have helped them in understanding the qualities of a leader, and also to further triangulate their responses on their LS. Students reported that they are more aware about the importance of being a good leader after attending this experiential outdoor learning camp. Some recommendations and ideas fromOBEC module designed are discussed.
\end{abstract}

Index Terms-Leadership camp, leadership activities, outdoor based environment, outdoor-based education camp, soft skills.

\section{INTRODUCTION}

Leadership skill (LS) is the key to master all other skills. LSentails the ability to lead in various projects. It is essential that students are able to understand the role of a leader and a group member and be able to carry out those roles interchangeably [1]. According to [2], it is important to be a leader who has clarity as a leader with clarity will have greater influence on the followers. Reference [2] further emphasized that followers will choose to give their attention to the most coherent communicators who knows how to give instructions. Good LSalso comes in a package with other soft skills like teamwork, communication, critical thinking, problem solving, etc. It is an all rounded skill where candidates with good LS are always at the top of most employers' choice. It is essential to promote the importance of LS among undergraduates through student development activities. Among others, outdoor-based education (OBE) activities are seen to be one of the most famous ways to enhance students' LS.

\section{A. Outdoor-Based Education}

OBE camp module intended to develop undergraduates' social and personal outdoors adventure, and environmental

Manuscript received October 1, 2014; revised December 5, 2014. This work was partly supported by the Malaysia Ministry of Education under Fundamental Research Grant Scheme.

The authors are with Universiti Tenaga Nasional, Putrajaya Campus, Selangor, Malaysia (e-mail: evelyn@uniten.edu.my, rosmiza@uniten.edu.my, manwar@uniten.edu.my, husni@uniten.edu.my, nurshuhaida@uniten.edu.my, farhaniza@uniten.edu.my, arif@uniten.edu.my). commitment skills [3], which further enhance their LS. It is defined as a form of outdoor education, which involves participants spending at least a night in outdoor settings [4]. Participants were exposed to a campsite that varies in their infrastructure ranging from basic to a fully equipped centre. The camp might occur in either two types of programs: 1) base camp, and 2) expeditionary.

Reference [5] defined OBE as "out-of-doors, contains elements of adventure, and is educational". The educational aspects of OBE culture increase the growth and development of participants in terms of attitudes, behaviours, personalities, characters and so on, while the aspects of adventure and outdoor heighten participants' experiences in emerging their self-efficacy and self-esteem. The secluded environment also plays a crucial role in developing students' LS.

The OBE Camp module comprises eight leadership-based activities designed for this study. The camp is set in a remote and less comfortable environment that are intended to raise students' consciousness about the importance of survival in an almost zero entertainment environment. Participants are restricted from the access of Internet or any sources of entertainment but merely nature than concrete.

\section{B. Outdoor Experiential Learning}

Part of the experiential learning model by [6] is referred. Reference [6] indicated that students learn from a cycle of four processes, that they must participate for learning to occur most completely. The cycle emphasizes learner's involvements in the learning itself. From the involvement in the activities designed, learners reflectedby voicing out their opinions to the activity moderator on the experiences gained from many positive aspects to seek for understanding (reflective observation). From all the reflections learners made, logical conclusions (abstract conceptualization) are drawn to help them relate the activities and theories learned which would finally lead to the decisions and actions (active experimentation) that establish new experiences (concrete experiences).

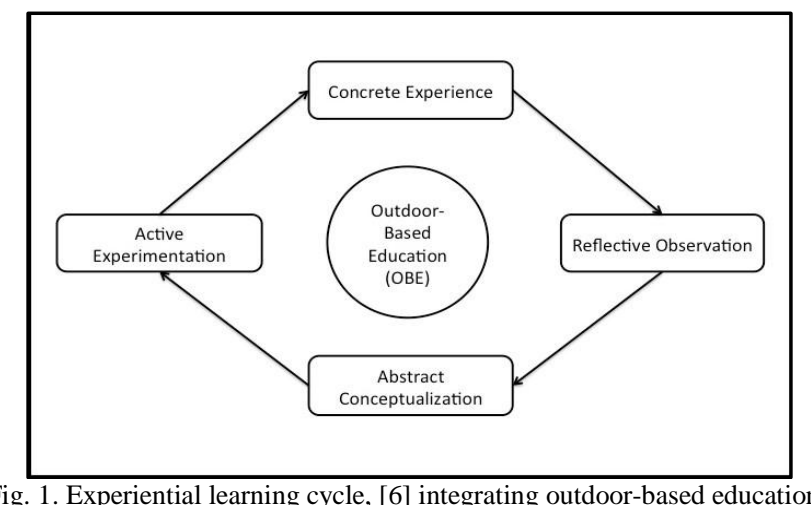

Fig. 1. Experiential learning cycle, [6] integrating outdoor-based education 
For example, when participants are involved in activities conducted in the camp, hands on,reflection will be done by themselves by adding many viewpoints from their prior knowledge. After that, students will draw a conclusion from what they have done with the activities by adding in the skillslearned. Then, it will guide them to make decision that will then be added to their new concrete experience in mind.

Ref. [7] further emphasized that adventure education or outdoor education draws on the philosophy of experiential learning where learning through reflection is applied. Their study found that self-awareness is the key characteristic of leadership development. Through OBE, which is set to take participants out of their comfort zone, they tend to be more aware about their own weaknesses and strengths that will help them improve as a person. This reflective process through hands on experiences in the camp, will then contribute to a life changing experiences.

\section{MethodOlOGY}

\section{A. Research Design}

This is an exploratory study done to gauge students' responses through self-assessment of their leadership skills after going through the Outdoor-based Education Camp, which utilized eight leadership modules.

\section{B. Participant}

A total of 43 UNITEN undergraduates were involved in this study. The students selected for this study had to first pass the interview stage where several questions regarding their achievements in schools were questioned. Students were selected based on their willingness to learn.

\section{Procedure}

The camp was conducted for three days two nights employing a set of eight leadership modules. On the first day of the program, students selected were first underwent training through workshops on leadership skills conducted by experts. Then, students were participated in the camp by applying what they hadlearned from the workshops. Throughout the camp, the researchers had observed the students' behaviors. At the end of the camp, students responded to a set of questionnaire, they were then randomly selected to be interviewed based on the observation done. Those seen with the most improvement were selected to be interviewed.

\section{Location}

The camp was conducted at Mak Lang Nature of Life, JandaBaik, Pahang. Students were required to stay in an outdoor and nature setting in the forest beside the river, out of their comfort zone.

\section{E. Instruments}

The questionnaire used was adapted from [8]. Clark set a guideline as follows:

175 and above - well on the way to becoming a leader.

125 to 174 - Getting close to becoming a leader.

124 and below - Not yet ready to becoming leader.

While a set of interview questions were constructed among the researchers to gauge students' feedbacks on the camp and to further triangulate their self-assessment about their LS.

\section{OUTDOOR-BASED EDUCATION CAMP}

\section{A. Concept of the Camp}

The camp was designed to train students both physically and mentally. A number of 20 students were first trained to become student trainers before the camp. A gap was created between the student trainers and participants where the participants were not allowed to be too close with them. Two of the student trainers were assigned role play characters. One of them acted as a strict and stern disciplinary trainer, while the other acted as a soft-spoken and motivational disciplinary trainer. On the other hand, two other student trainers were assigned to be the joyous trainers who were in charge of games and fun. This leads to roller coaster like and fluctuating emotional stages where participants endured mixed emotions. Participants were encouraged to not give up and be persistent for the trainers will then relate the situations with real life experiences.

Furthermore, students were not allowed any form of technological devices including hand phones. It was to get them to be fully focused on activities conducted. Other than that, punctuality was one of the most emphasized value in the camp. When one participant reached the place where activity was conducted late, he or she will be punished.

At the end of every single activity, participants were asked about what they have learned from the activity conducted. At the end of the camp, they were then asked to do an overall reflection on what they have learned by voicing out their opinions.

\section{B. Eight Leadership-Based Activities}

These activities were designed to promote overall leadership skills among students. Activities conducted also promoteother soft-skills like teamwork and communication.

\section{Paper Snooker Ball}

This activity was carried out to instill leadership skills and the ability to work in a team. Furthermore, it was designed to introduce the virtue of patience when working on something. Participants were required to work in a team to finish tasks assigned.

\section{The Blind and the Deaf}

This activity was conducted to sharpen the participants' communication skills, by teaching them how to convey information effectively. It was also designed to inculcate the idea of being a good leader, they must first be a good follower. They need to work together in a team to get the blind and the deaf to finish tasks assigned.

\section{E. One Choice Wrecking Ship}

The objectives of this activity is to help them discover the true self about each of their teammate. Pushing their patience to the limit to train them how to control their emotion in stressful situations. It is also to enhance their decision making skills where in a ship wrecking situation, they have to decide whom they should save first.

\section{F. Poisonous Candy}

This activity was done in a few stages. Participants were required to make instance decision in a limited time. The objectives of this activity is to instill critical thinking skills among the participants. They have to think wisely before any 
action is taken.

\section{G. Save the Egg}

Participants were given limited materials to protect a fragile egg given to each group. They were required to think creatively and critically on how to prevent the eggs from breaking when it was thrown from a certain height by the trainer. The main objective of this activity is to inculcate problem solving skills and teamwork among participants.

\section{H. Survival Challenge}

This is a series of tasks stationed at different parts of the camp site where students were required to finish all the tasks at every station in order for them to obtain ingredients and cooking utensils. This challenge was designed to enhance teamwork among participants.

\section{River and Jungle Tracking}

This is the traditional method of getting students into fully outdoor setting with expedition. Students had to follow through a series of toughness through the path set deep into the jungle. Students were also instructed to walk a long distance against the strong current of the river. It was the most challenging activity. This activity trains students' patience and endurance in achieving goals.

\section{J. Tallest Tower}

This activity required students to build the tallest tower using limited materials given to them. It was a competition among the groups. Whichever team got the tallest and most stable tower will win the challenge.

\section{RESULTS AND DISCUSSION}

\section{A. Survey}

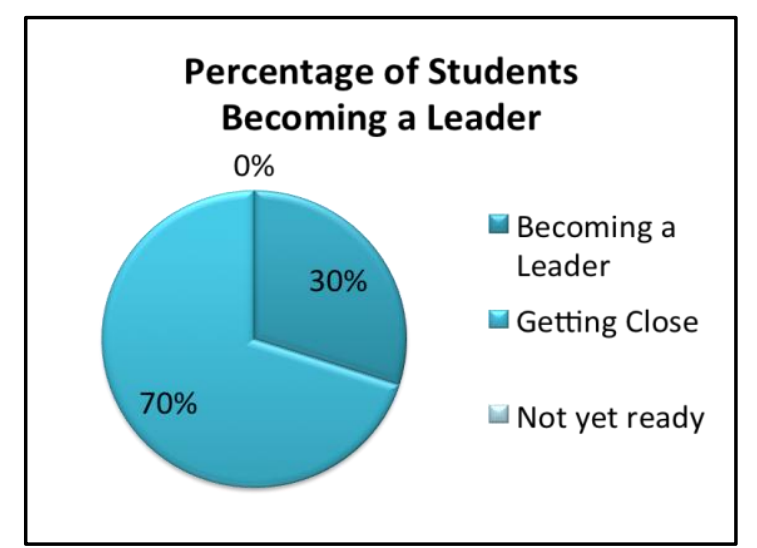

Fig. 2. Percentage of students' self-assessment of becoming a leader.

Fig. 2 shows that all students who went through the camp are becoming a leader. $70 \%$ of the respondents are becoming a leader. It illustrates that students who reported that they are becoming a leader are having high level of confidence and believing that they are already a leader. $30 \%$ of the students are well on the way to becoming a leader. It delineates that they are not yet a leader but they are all gear up to become a leader. Fortunately none are not yet ready to become a leader.

\section{B. Interview}

From the interview, overall, students responded that they learned to become a good leader from the activities conducted with the concept of the camp. Below are excerpts from the interview:

1) What have you learned from the activities conducted in the camp?

"I've learned how to be flexible in any situation given. We need to have backup plan at least one." Jio

"I've learned that a person is able to become better, by having a correct mindset and a proper training experience. The Leadership Camp provides me all of that." $\sim$ Afiq

"From this camp, I learned how important to trust myself first before I do something and to be a better person, we need to get out from the comfortable zone. Like in this camp, I need to take a role totally different from my character. But by challenging myself, I know that I can do this." $\sim$ Syidi

"Being flexible in planning activities has always been one of my weaknesses. This camp became a stepping stone for me to improve myself in that aspect by learning to decide and carry out other activities instantly when things do not follow as planned. " Callie

"From the camp, I found out my true strengths and weaknesses. I found that I'm not such an observant person and I'm not able to analyze things quickly when the problem is given. But I believe that I'm able to provide creative solutions and I'm good in critical thinking." $\sim$ ShinChan

"In the camp basically I have learned a lot of things. The most important is leadership skills. For every activity or module, we need to have a leader in order for us to manage the given task. Without proper leadership skills we might get stranded without achieving the goal." Sarrvin

"From the camp, I have learned many things, but the one thing that I have learned most is how to make a decision based on various situations. " Aizat

From theanswers for question 1, generally, students responded that they are able to lead a program after participating in the camp. Most importantly, they are conscious and confident that they have learned some important skills in the camp.

2) You said that you are becoming a good leader after joining the camp. In what way are you becoming a good leader?

"I am able to lead others to manage activities. I can now speak in front many people. I am not afraid of having eye contact when talkingin front of many people and I am able to use body language to attract others' attention when speaking." Jio (Communication skills)

"My life before this was very timid, afraid of small challenges and the camp provided the change that I necessarily need. A good leader for me is Loyalty and Respectful to others. Confidence is in the context of what the Camp has provided me." Afiq (Courage and Confidence)

"A good leader needs a good organization. For me, I am becoming a good leader because I can handle or know how to deal with my teammates in achieving our goals. Like in this camp, each of us play their roles successfully and make this camp become awesome." Syidi (Teamwork)

"For this camp, I have learned how to lead the others. This further teaches me that a leader must always have contingency plans to ensure that a program runs smoothly. I 
am having that skills now. " Callie (Responsibility)

"Through the activities and modules with my teammate, I

found out how to compliment my strength to make up for their weaknesses and vice versa. Hence I believe that I'm becoming a good leader by working together with my team and trusting their abilities." ShinChan (Teamwork)

"After attending the camp, I can see the improvement by being a good leader. I can be specifically said in terms of respect. As a leader we were trained to accept other people view even though it is contradict with your believe." $\sim$ Sarrvin (humbleness and respect).

"I am able to distribute tasks accordingly to my colleagues and make sure that it is going according to plan, and by plan means including the backup plan. Even though there's a lot of activities that need a change of plan, we are able to act accordingly, and that help me to become a great leader." Aizat (planning and management)

From the excerpts stated above, students seem to be confident that they are becoming good leaders through the acquisition of different skills from the camp. Most importantly, they know what they have learned from the camp and they are applying the skills they acquired from the camp.

\section{CONCLUSION}

In conclusion, the study was initiated with the main objective to find ways to help students in acquiring leadership skills. The focus of the OBEC was mainly on leadership skills, communication skills and teamwork. However, students' discipline and ethic throughout the program were equally important. Furthermore, the other skills like critical thinking and problem solving skills were cultivated indirectly through the program as those are the skills required to participate in the activities. It is hoped that this outdoor-based education camp will contribute to the fulfillment of the national educational philosophy by producing graduates who are balance physically, emotionally, intellectually and spiritually. A module that is most suitable for soft-skills development will be compiledfor the use of future program.However, further research needs to be conducted to test the modules more thoroughly. More activities will be added.

\section{ACKNOWLEDGMENT}

The authors would like to first thank God for the success of this study. The authors would also like to thank Universiti Tenaga Nasional for the support in completing this study.

\section{REFERENCES}

[1] Ministry of Higher Education Malaysia, Development of Soft Skills for Institutions of Higher Learning, Universiti Putra Malaysia, 2006.

[2] T. Dewan and D. P. Myatt, "The qualities of leadership: Direction, communication, and obfuscation," American Political Science Review, vol. 102, pp. 351-368, 2008.

[3] M. A. M. Taff, A. Aziz, R. N. S. R. Haron, N. M. Rasyid, and M. M. Yasim, "Residential outdoor education and environmental attitudes: An examination in a Malaysian university," Journal of Outdoor Recreation, Education, and Leadership, vol. 2, no. 3, pp. 198-216, 2010.

[4] S. B. Hill, "Camping to change the world," Australian Journal of Outdoor Education, vol. 8, no. 1, pp. 60-68, 2004

[5] J. Sibthorp and J. Jostad, "The social system in outdoor adventure education programs," Journal of Experiential Education, vol. 37, no. 1, pp. 60-74, 2014
[6] D. A. Kolb, Experiential Learning: Experience as a Source of Learning and Development, New Jersey: Prentice Hall. 1984.

[7] C. E. Draper, C. Lund, and A. J. Flisher, "A retrospective evaluation of a wilderness-based leadership development programme," South African Journal of Psychology, vol. 41, no. 4, pp. 451-464, 2011.

[8] D. Clark. (2004). Concepts of Leadership. [Online]. Available: http://nwlink.com/ donclark/leader/leadcon.html

[9] D. Clark. (2012). Design methodologies: Instructional, thinking, agile, system, or $\mathrm{x}$ problem? [Online]. Available: http://nwlink.com/ donclark/design/design_models.html

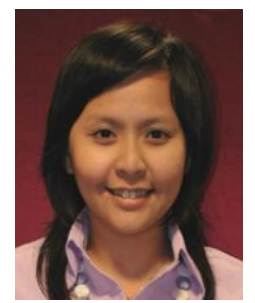

Evelyn Ewe Lin Yeap was born in Taiping, Perak, Malaysia. She graduated with B.Edu. in the teaching english as a second language (TESL), Universiti Putra Malaysia, Selangor, Malaysia, 2007; M.Sc. in the teaching English as a second language (TESL), Universiti Putra Malaysia, Selangor, Malaysia, 2012. She is currently an academician in the Department of Languages and Communication, College of Foundation and General Studies (CFGS), Putrajaya Campus, Universiti Tenaga Nasional (UNITEN). She has been in UNITEN since 2008. Yeap was appointed as the head of Unit for Student Development under CFGS. In 2011, she received an Excellence in Student Development Award presented by the Vice Chancellor of Universiti Tenaga Nasional. She has trained students in a number of leadership camps, and she is in the process of compiling the module for outdoor education camp.

Miss Yeap devotes her passion in teaching and research. Her areas of study include communication competence, leadership, outdoor education, soft-skills enhancement, public speaking anxiety, teaching materials, and positive student development.

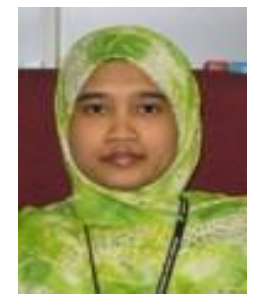

Rosmiza Mokhtar was born in Dengkil, Selangor, Malaysia. She graduated with B.Sc. (Hons) in applied optics, 1995, M.Sc. in applied optics, 1999, and $\mathrm{PhD}$ in applied optics, 2008, from University Universiti Putra Malaysia, Selangor, Malaysia. She is currently the deputy dean of Student Affairs and External Relations under College of Foundation and General Studies (CFGS), Putrajaya Campus, Universiti Tenaga Nasional (UNITEN). She has 12 years of teaching experiences.

She is passionate in nurturing students to adapt and well prepared in term of academic skills. She also prepares a platform for the students to experience the real situation, sharpened their skills in leadership, communications entrepreneurship and time management.

Dr Rosmiza's areas of study include applied optics, teaching and learning and student development.

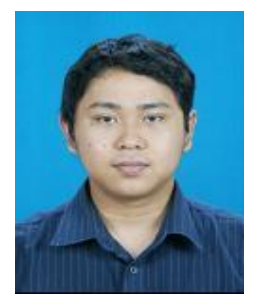

Mohd Anwar Muslimen was born in Tampin, Negeri Sembilan, Malaysia. He obtained his B. Sc. (Hons) in computer science (software engineering) from Universiti Putra Malaysia, Selangor, Malaysia, 2009.

He is currently an academician in the Department of Sicence, Mathematics and Computing, College of Foundation and General Studies (CFGS), Putrajaya Campus, Universiti Tenaga Nasional (UNITEN). He has trained students in a number of leadership camps mostly in charge in outdoor expedition.

Mr Mohd Anwar is passionate in teaching and research. His areas of study include leadership, outdoor education, soft-skills enhancement, system networking, and programming language.

Nurshuhaida's research areas include oral communication strategies, leadership communication, project-based learning, experiential learning and second language acquisition.

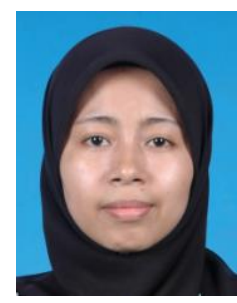

Farhaniza Ghazali was born in Jeli, Kelantan, Malaysia. She graduated with B.Sc. mathematics (statistics), University of Malaya (UM), Malaysia, 2007.

She is currently an academician in the Department of Science Mathematics and Computing (SMC), College of Foundation and General Studies (CFGS), Putrajaya Campus, Universiti Tenaga Nasional (UNITEN). She has been in UNITEN since 2008.

Farhaniza was appointed as the head of Programme for Preparatory Programme For Excellent Students (PPES) under CFGS. In 2011, she received the Promising Academicians Awards in Excellence and Innovation, Teaching and Learning Category presented by the Vice Chancellor of Universiti Tenaga Nasional. She has guided students in a number of 
community service programmes organized in Malaysia and outside Malaysia.

Miss Farhaniza devotes her passion in teaching and research. Her areas of study include communication competence, leadership, outdoor education, soft-skills enhancement, mathematics anxiety, teaching materials, positive student development.

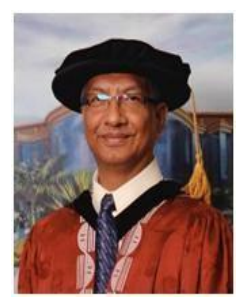

Mohd Ariff Ahmad Tarmizi was born in Ipoh, Perak, Malaysia. He graduated with B.Sc. in distributive education, Western Michigan University, US in 1982; M. Edu. audio visual media and M. Edu. Teaching Community College, Western Michigan University, US in 1983 . He is currently the dean of College of Foundation and General Studies (CFGS), Universiti Tenaga Nasional (UNITEN). He has started his teaching career since 1983 .
He is passionate with student development as he had advised students in many community services project internationally. He has a lot of international recognized experiences in his area of area.

$\mathrm{Mr}$ Ariff's research areas are mainly focused on teaching and learning and entrepreneur leadership. 